\title{
Cultura de Masas y mediaciones
}

Mass Culture and Mediation

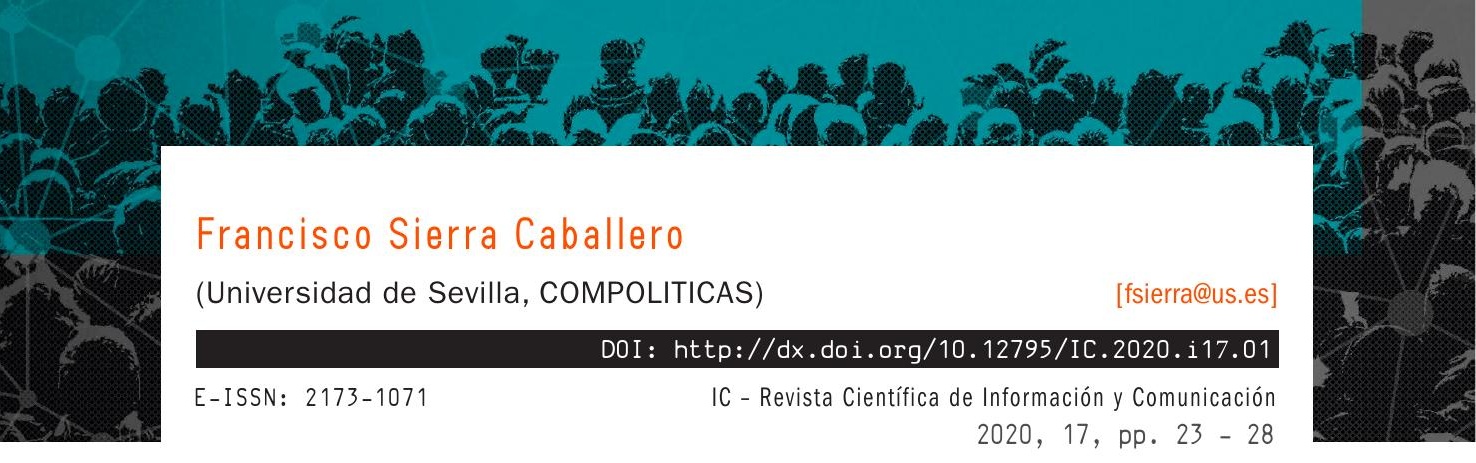

Decía Blaise Pascal que lo contrario de una verdad no es el error, sino una verdad contraria. En estos tiempos convulsos de pandemia y crisis de régimen, cuando la Universidad procura estabilizar lo inevitable es tiempo de reformular el sentido de la práctica teórica y la razón de ser de una revista científica de departamento. En medio de la crisis, la oportunidad de debatir y pensar el modelo de difusión de conocimiento ha dado lugar a iniciar un nuevo período en la historia de la Revista Científica de Información y Comunicación, un proyecto colectivo departamental que un grupo de compañeros iniciamos con el proferos Manuel Bernal Rodriguez, fundador y primer responsable de la revista, y que ahora ha de abrir espacios y procesos acorde a nuevos actores y un contexto emergente que necesariamente ha de ser tomado en cuenta para cumplir con la misión originaria de la misma. Cuando la Universidad es una casa de citas 0 , peor aún, la razón de ser que la mueve como institución es la caza de citas -0, lo que es lo mismo, la fulgurante ascensión en el universo de los rankings y la eficiencia tecnológica-, puede decirse que la academia ha muerto y que el sentido de una publicación como la que vislumbramos ha de reorientar en dirección contraria a la dialéctica de la privatización del conocimiento y del neopositivismo reinante, en contra, 
en fin, de la racionalidad instrumental que todo lo inunda. Un reto nada novedoso en la historia del pensamiento y en el propio debate de las Ciencias Sociales. Hace décadas, Adolfo Sánchez Vázquez advertía que uno de los principales peligros que acecha a la civilización y a la cultura modernas es justo la ideología tecnológica, el fetichismo, la vocación nihilista y encubridora de la tecnocracia como forma perfeccionada de la negación política y, a fin de cuentas, del propio dominio público. En la era de jcerrilismo, como criticara el profesor García Gutiérrez, la cuestión nuclear es si, pensando en la Revista I/C, puede una universidad pública asumir tal racionalidad sin socavar sus propios fundamentos. Y la repuesta, a nuestro juicio, es clara: desde luego que no. Y lo podemos corroborar hoy que la pandemia ha convertido la universidad en sucursales de los GAFAM (Google, Amazon, Facebook, Apple y Microsoft), usando Zoom, Team, Blackboard y otras herramientas tecnológicas que avanzan en la siliconización del universo social, el sueño húmedo de Manuel Castells y otros apologetas de la vacuidad tautológica propia de la racionalidad tecnocentrista.

El peligro de tal deriva es bien conocido. Como en el film de Wim Wenders, Hasta el fin del mundo, que proyecta la distopía del nuevo milenio, donde personajes como Trevor, interpretado por William Hurt, transitan en un mundo globalizado -de Tokyo a París o Nueva York- para terminar en Australia mostrando a su madre ciega las imágenes y recreaciones de lo soñado y visto para su recreación, en un universo completamente digitalizado, donde reina la comunicación total, la lección que hay que aprender de esta película es clara.No hay vida -ni pensamiento, diríamos- que no cultive el culto a la acción. No hay filosofía sin praxis, ni ciencia sin trabajo sobre lo real. El culto a la tecnología y el fetichismo de la técnica es la muerte de la razón y de la propia función social del conocimiento. El pensador francés Lucien Sfez definía esta dinámica propia de las sociedades tautistas que realimenta una cultura cerrada en sí misma, autista, cuya justificación es, a todas luces, puramente tautológica, como un asalto, en fin, a la razón y toda lógica para la vida en común.

La era de la Inteligencia Artificial y del teletrabajo inaugura, gracias a la caja negra del dominio de la razón técnica, el tiempo opaco de la gestión de las multitudes por el algoritmo y el control a distancia, a veces en forma de estricto autocontrol. Asistimos así a la explotación intensiva de una economía inteligente que, como estamos viendo, empieza por derruir la factoría del conocimiento, gran paradoja, en fin, la de la universidad digital a distancia, más virtual que real, sometida a los gigantes de cien ojos que todo lo ven, a lo Argos Panoptes, con la consabida transferencia de información de dominio público a corporaciones privadas y de datos sensibles, de investigación y desarrollo 
a compañías como Microsoft, tal y como hizo la Universidad de Sevilla con el correo electrónico y la consecuente protesta de todo el personal docente y de administración y servicios sin respuesta de las autoridades académicas. Y en este grave error se persiste sin razón, conocimiento ni el debido distanciamiento.

Pero no es tiempo de lamento sino de cuestionar la dirección o curso de los acontecimientos en nuestras universidades, comenzando, como decía Marx, por formular las preguntas impertinentes que son, hoy por hoy, las más necesarias.

Así por ejemplo, ¿qué productividad es esta de un sistema, tipo Amazon, en el que los propios trabajadores saben y sufren la imposibilidad de responder a la irracionalidad de un algoritmo dictado por máquinas de no dormir? ¿0 qué sentido tiene incorporar aplicaciones de código cerrado teniendo escuelas y facultades de Ingeniería Informática y capacidades sobradas, sin externalizar, para el desarrollo de sistemas apropiados, por no mencionar la existencia de herramientas accesibles de código libre, tipo Moodle? 0 para qué editar una revista sujeta o condicionada por indicadores nunca discutidos según una lógica industrial de puro fordismo-taylorismo.

Sabemos, no se olvide, que la ausencia de soberanía tecnológica es la renuncia a un proyecto propio de educación superior, la subalternidad y dependencia de los gigantes estadounidenses o asiáticos y que por definición toda actividad investigadora consustancial a un departamento universitario exige transferencia de conocimiento y difusión del saber, hacia la comunidad científica, y los pares, tanto como la propia sociedad y lectores interesados en el saber comunicológico contemporáneo. Ahora, una universidad robotizada es una universidad que no sueña, y el sueño de la y razón, que no siempre produce monstruos cuando depende de la tecnocracia, tiende a imponer una administración electrónica sin sentido, y una evaluación de la productividad científica absurda y siempre al hilo del oxímoron como propuesta, porque no siente en función del nuevo pitagorismo de lo ridículo o innombrable.

De la tecnocracia a la dedocracia, del universo Uber a la comida rápida, vamos a un modelo de Universidad de consumo bajo demanda, orientada al modelo estadounidense, que es tanto como decir que la enseñanza es hoy un producto de usar y tirar. La ética del saber es remplazada por la vigilancia electrónica y la cultura académica socrática desplazada por el like de un alumno-consumidor que tiene siempre la razón, 0 las citaciones y prestigio de la netputación, que poco o nada exige en términos de consistencia y calidad del trabajo autónomo.

Andamos, en fin, en el universo Disneygoogle. Un campus no apto para la inteligencia crítica. Al menos de momento, pues estamos convencidos que todo se 
andará. Como en otros luminosos períodos de la historia, el fracaso de la cibernética de salón tiene los días contados. Paciencia a los académicos: la vida late más allá de las máquinas. No olvidemos que la práctica teórica se sitúa siempre en la realidad social y concreta.

Si la historia de cada hombre o mujer es, como pensaba Brecht, simplemente contingencia y narratividad, no hay escritura ni imaginario posible que no pase por confrontar productivamente la mediación entre lo material y la proyección simbólica de la vida social, que no proyecte lo real y lo imaginario. Este principio es inexcusable y necesario en toda actividad de pensamiento no idealista, el alfa y omega de la crítica que consiste, básicamente, en aprender a pensar de otro modo, desde otra posición, articulando el sentido de la crítica como una crítica del sentido común. Desde este punto de vista, la autoría constituye una función pública de articulación de espacios de recuerdos y omisiones, trenzando constelaciones de patrimonio simbólico para el acuerdo o la controversia, más aún si se trata de un contexto tan colonizado como actualmente el sistema de ciencia y tecnología que nos emplaza a tratar de realizar un ejercicio de observación y el debido distanciamiento crítico con la lógica que subsume y empobrece la actividad intelectual, sea por el efecto ANECA o una mal entendida lógica de evaluación y validación de la calidad de la actividad investigadora. Frenta a esta lógica de captura del trabajo creativo, más aún siendo nuestro ámbito el área de la Comunicación, la Revista I/C inicia esta nueva etapa proponiéndose abrir el pensamiento a la crítica, y la tarea de la difusión a la radical voluntad de construir comunicología como ciencia aplicada en común, empezando por la forma de producir y diseñar la revista, de acuerdo a las propuestas que vienen produciéndose en Europa y América tras la Declaración de San Francisco.

En resumen, el lector puede encontrar aquí, a partir de esta nueva etapa, caminos y lecturas potenciales para repensar el campo de la mediación social en nuestro presente y develar el sentido de las nuevas construcciones ideológicas y el espesor material de los relatos de la crisis y contradicciones que atenaza también la propia academia. Si hemos de vindicar la MEMORIA que es tanto como definir lo común en un sentido proyectivo, para construir las bases de la Comunicología como filosofía de la praxis, es hora de redefinir la línea editorial de I/C como una POLITICA DE LO COMÚN en términos de una visión dialógica de la práctica teórica que hace posible la ciencia en sociedad frente a toda estrategia tecnocrática o instrumental. En la era del perfilado, estamos convencido que dicho trabajo es prioritario. En un momento en que la incertidumbre, la duda, el riesgo y la excepción se imponen y aumentan las incertezas ingresando la comunicación 
en una zona de nebulosas, de desprotecciones y de espacios fronterizos, es hora de contribuir a una nueva mirada cultivando la crítica de la crítica en su triple eje: practico, teórico y de acción. Pues, nunca como hoy, somos conscientes que el quehacer científico implica transformar, definir y subvertir el orden reinante. Esperemos que el trabajo del nuevo equipo editorial contribuya a ello. Es el mejor servicio que puede dar la academia a las urgentes demandas que apunta la Ilamada sociedad digital. 
